\title{
The pleiotropic roles of sphingolipid signaling in autophagy
}

This article has been corrected since Online Publication and a corrigendum has also been published

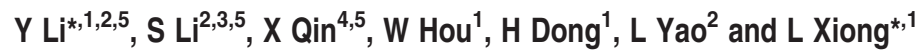

The autophagic process involves encompassing damaged proteins and organelles within double- or multi-membraned structures and delivering these molecules to the lytic compartments of vacuoles. Sphingolipids (SLs), which are ubiquitous membrane lipids in eukaryotes, participate in the generation of various membrane structures, including rafts, caveolae, and cytosolic vesicles. SLs are a complex family of molecules that have a growing number of members, including ceramide, sphingosine-1-phosphate, and dihydroceramide, which have been associated with the essential cellular process of autophagy. This review highlights recent studies focusing on the regulation and function of SL-associated autophagy and its role in cell fate, diseases, and therapeutic interventions.

Cell Death and Disease (2014) 5, e1245; doi:10.1038/cddis.2014.215; published online 22 May 2014

Subject Category: Cancer Metabolism

Facts

- Autophagy is generally considered to be a cell survival mechanism and may also contribute to cell death, depending on its various biological contexts.

- Sphingolipids were first discovered in brain extracts in 1876, and within a century of intensive research, the chemical structures of thousands of individual sphingolipids had been elucidated.

- Sphingolipid-associated autophagy contributes to a range of diseases, including neurodegeneration, tumors, metabolic disorders, and heart diseases.

\section{Open Questions}

- Sphingolipids are abundant lipid components of eukaryotic plasma membranes that function in a wide range of biological processes. Are sphingolipids involved in the composition of autophagic membranes?

- Why do perturbations of sphingolipid metabolism by chemotherapy and nutrition starvation trigger lethal autophagy and protective autophagy, respectively?
- Sphingolipid-mediated signals that have long been known to induce apoptosis are now also recognized to cause autophagy. Are sphingolipid-associated apoptosis and autophagy interlinked?

- How does sphingolipid-associated autophagy occur and to what extent do alterations in autophagy contribute to disease phenotype?

- What drugs or compounds that target sphingolipid metabolism are attractive candidates for therapeutic development?

Autophagy is generally considered to be a cell survival mechanism, and this process also contributes to cell death in several situations. ${ }^{1}$ Sphingolipids (SLs) are ubiquitous components of membrane structures, and renewed interest in SLs has focused on SL-induced intracellular and extracellular signaling. ${ }^{2}$ Accumulating evidence indicates that a direct link exists between SL metabolism and autophagy. Moreover, studies have uncovered that a dynamic balance among SL metabolites is significant in cell fate determination. ${ }^{3,4}$ Here we review the key aspects of bioactive SLs that have emerged as important effectors in regulating the autophagic pathway, mediating the cross talk between apoptosis and autophagy,

\footnotetext{
${ }^{1}$ Department of Anesthesiology, Xijing Hospital, The Fourth Military Medical University, Xi'an 710032, China; ${ }^{2}$ The State Key Laboratory of Cancer Biology, Department of Biochemistry and Molecular Biology, The Fourth Military Medical University, Xi'an 710032, China; ${ }^{3}$ Department of Oral Biology, Stomatology School, The Fourth Military Medical University, Xi'an 710032, China and ${ }^{4}$ Department of Chemistry, Pharmacy School, The Fourth Military Medical University, Xi'an 710032, China ${ }^{*}$ Corresponding authors: Y Li, The State Key Laboratory of Cancer Biology, Department of Biochemistry and Molecular Biology, The Fourth Military Medical University, 169 Changle West Road, Xi'an, Shaanxi 710032, China. Tel: +86 2984774516 8017; Fax: +86 29 84774513; E-mail: liyann@fmmu.edu.cn

or L Xiong, Department of Anesthesiology, Xijing Hospital, The Fourth Military Medical University, 127 Changle West Road, Xi'an, Shaanxi 710032, China. Tel/Fax: +86 29 84775012; E-mail: mzkxlz@126.com

${ }^{5}$ These authors contributed equally to this work.

Keywords: autophagy; sphingolipids; sphingolipidoses; sphingolipid rheostat; sphingolipid biostat

Abbreviations: 4-HPR, 4-hydroxy (phenyl) retinamide; aCDase, acid ceramidase; Atg, autophagy-related gene; CDase, ceramidase; Cer, ceramide; CerS, Cer synthase; dhCer, dihydroceramide; ER, endoplasmic reticulum; GCase, glucocerebrosidase; LC3, microtubule-associated protein light chain 3; mTOR, mammalian target of rapamycin; NPC, Niemann-Pick disease type C; PI3K, phosphatidyl inositol 3-kinase; S1P, sphingosine-1-phosphate; SL, sphingolipid; SMase, sphingomyelinase; SphK, sphingosine kinase

Received 17.9.13; revised 10.4.14; accepted 15.4.14; Edited by C Munoz-Pinedo
} 
and determining the associated cell fate. A deeper understanding of the relationship between SL metabolism and autophagy explains how intact or impaired SL-related autophagic pathways are involved in the malfunctions associated with neurodegeneration, cancer, and other diseases. We also discuss how autophagy-regulating drugs work via cells' SL metabolism and the methods that could be used to monitor SL-related autophagy. Present and future investigations regarding SL-related autophagy will help to develop novel treatment strategies to control autophagy-related diseases.

\section{The SL Family}

SLs represent a significant class of lipids that contain a backbone of sphingoid bases and are ubiquitous constituents of membranes in eukaryotes. SLs were first discovered in brain extracts in $1876,{ }^{3}$ and within a century of intensive research, the chemical structures of thousands of individual SLs had been elucidated. ${ }^{4}$ The SL metabolic pathway displays an intricate network of reactions that result in the formation of multiple SLs, including ceramide (Cer), dihydroceramide (dhCer), and sphingosine-1-phosphate (S1P). ${ }^{5}$

SLs are produced in at least three distinct ways (Figure 1). First, a substantial portion of SLs are derived from de novo biosynthesis in most organisms, ${ }^{2,6}$ with the condensation of serine and palmitoyl-CoA catalyzed by serine palmitoyl transferase to generate dehydrosphinganine. Dehydrosphinganine is subsequently reduced to form dihydrosphingosine (sphinganine), which is then $\mathrm{N}$-acylated by dhCer synthase to produce dhCer or Cer. Second, through hydrolysis via a complex lipid-turnover pathway, ${ }^{2,6}$ several specific hydrolases are involved in the turnover process, including sphingomyelinases (SMases) and glucocerebrosidase (GCase). In addition to the above two sources, Cer is also recycled. ${ }^{6,7}$ In this pathway, sphingosine is recycled into Cer via Cer synthases (CerS); therefore, this pathway is also called the salvage pathway. The cellular metabolic homeostasis of the sphingolipidome is often achieved through the coordination of the biosynthesis and removal of SL species, which requires a delicate balance between de novo biosynthesis, turnover, and recycling. $^{8}$

SLs are found in cellular membranes, lipoproteins, and other lipid-rich structures; however, they are synthesized in the endoplasmic reticulum (ER) and Golgi apparatus. The scheme in Figure 1 depicts the subcellular localization of SL biosynthesis, turnover, and recycling. In addition, SLs may be incorporated into other intracellular compartments, such as mitochondria or autophagosomes. ${ }^{3}$ The turnover and recycling of SLs also occur at several intracellular locations, including the endosome, phagosome, and lysosome. ${ }^{3}$ Thus, SLs travel between organelles, and this transport occurs via either transport vesicles or transfer proteins. ${ }^{9}$ CERT (Cer transfer protein) and FAPP2 (four-phosphate adaptor protein 2) have proved to be two critical SL-trafficking proteins that regulate the trafficking of SLs to specific compartments within cells. ${ }^{10,11}$ Lipids are increasingly implicated in the control of the membrane remodeling and vesicle transport that underlie the biogenesis of autophagosomes. ${ }^{12}$ However, our knowledge of whether and how $\mathrm{SL}$ trafficking is associated with the autophagic process remains incomplete.

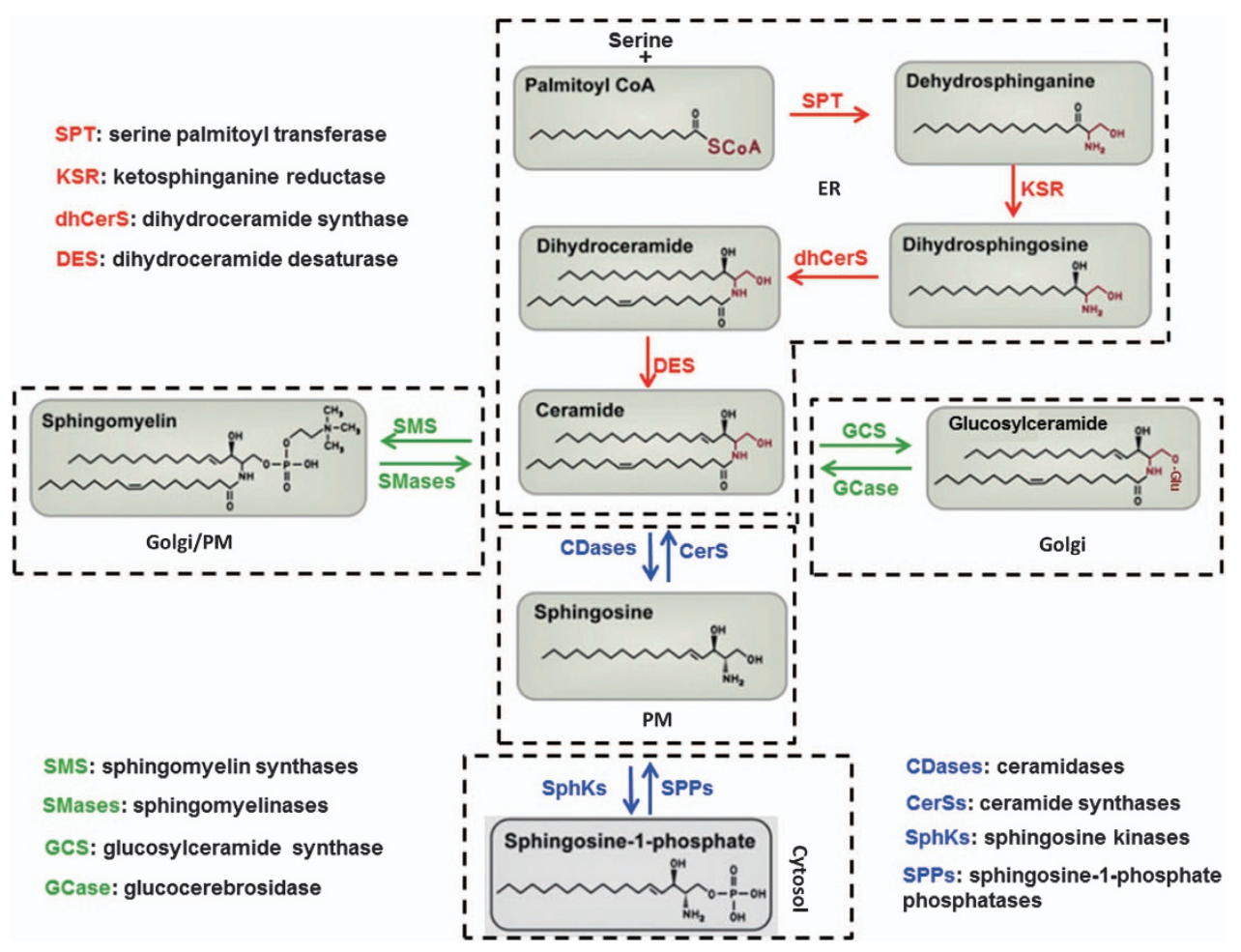

Figure 1 Cer formation through the de novo, turnover, or salvage pathway. Red arrows: de novo pathway; green arrows: turnover pathway; blue arrows: salvage pathway. PM, plasma membrane 
SLs are considered to primarily have roles as components of membranes and other biological structures. However, several SL metabolites, including Cer, dhCer, and S1P, have drawn attention as bioactive signaling molecules that mediate cell growth, differentiation, senescence, apoptosis, and autophagy. ${ }^{4,5}$

\section{SLs Involved in the Autophagic Pathway}

'Autophagy,' which is derived from Greek and means 'to eat oneself,' ensures the synthesis, degradation, and recycling of cellular components in eukaryotic cells ranging from yeasts to mammals. ${ }^{13-15}$ At present, the following three modes of autophagy have been identified: macroautophagy (which is commonly called 'autophagy,' including in this review), microautophagy, and chaperone-mediated autophagy. During the autophagic process, nonspecific or targeted cytoplasmic constituents are delivered to and degraded in the lysosome via these autophagic pathways. ${ }^{16,17}$ The formation of the autophagosome is a multistep process that includes the biogenesis of the isolation membrane, followed by its elongation and closure. ${ }^{18}$ Most autophagy-related genes (Atgs) contribute to autophagosome formation, and many are well conserved from yeasts to mammals. ${ }^{19,20}$

SLs are abundant lipid components of eukaryotic plasma membranes that function in a wide range of biological processes, ${ }^{21,22}$ which make SLs strong candidates as possible autophagosomal lipids. Several studies have implied that SLs, and especially Cer, are autophagosomal membrane components. ${ }^{23,24}$ In addition, SLs formed by de novo biosynthesis in the ER might be a driving force for the formation of the autophagosomal vacuole, in what has been referred to as the 'membrane extension' step, ${ }^{25}$ which occurs after many of the associated autophagosomal proteins have been recruited. Because the enzymes required for de novo Cer biosynthesis reside in the $\mathrm{ER}^{26}$ it is possible that they might be recruited into autophagosomes and perhaps continue to produce SLs there.

The best-characterized pathway regulating autophagy includes a class I phosphatidyl inositol 3-kinase (PI3K) and mammalian target of rapamycin (mTOR), which act to inhibit autophagy. Although how autophagy is suppressed by these molecular signals remains to be revealed, mTOR complex 1 (mTORC1) is known to phosphorylate the autophagy regulatory complex, ULK1 (containing unc-51-like kinase 1), the mammalian Atg13 protein, and focal adhesion kinase-interacting protein of $200 \mathrm{kD}$ (FIP200). ${ }^{27,28} \mathrm{~A}$ class III PI3K is needed for the activation of autophagy. ${ }^{4,16}$ SLs participate in cell survival and cell death signaling pathways. ${ }^{29,30}$ Complex autophagy regulation might be mediated by SLs or SL metabolism. Indeed, different bioactive SL species have been shown to mediate distinct autophagic pathways, described as protective autophagy and autophagy-associated cell death (Figure 2), which have opposing functions in cellular life-ordeath decisions. , $^{3,31}$

Cer, which is known to induce cell cycle arrest and has been implicated in important physiological roles in cell differentiation, senescence, migration, adhesion, and inflammatory responses, is the key intermediate in SL metabolism. ${ }^{6,32}$ Exogenous Cer-related autophagy was shown to trigger

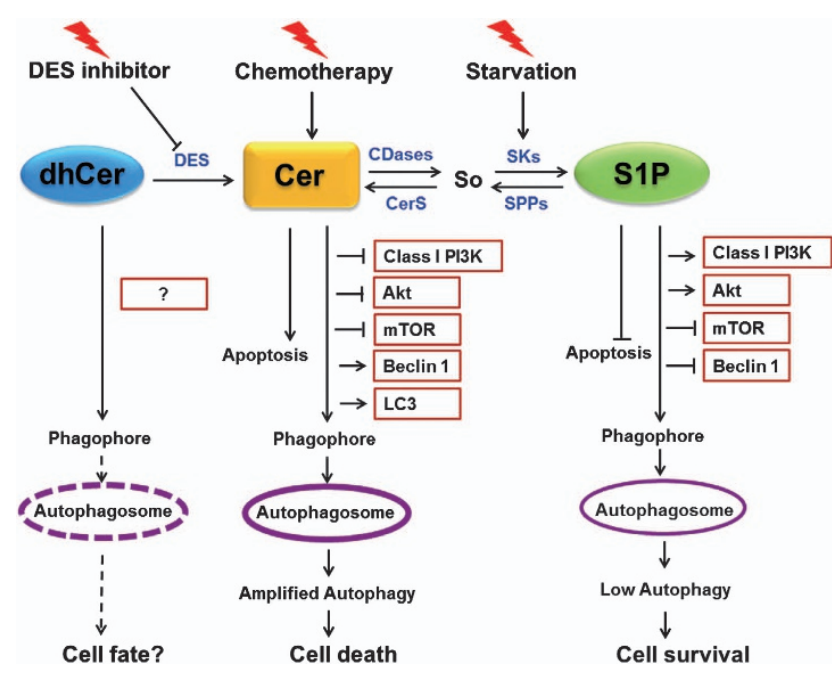

Figure 2 Model of SL-related autophagy and its consequences on cell fate. CerSs, ceramide synthases; DES, dihydroceramide desaturase; So, sphingosine; SPPs, sphingosine-1-phosphate phosphatases

autophagy-associated cell death, which occurs in several malignant cell types, including colon cancer, breast cancer, cervical cancer, nasopharyngeal cancer, and glioma cells. ${ }^{3,33-37}$ In addition to exogenous Cer, endogenous Cer species are critical for the induction of autophagy. Tamoxifen, an estrogen receptor antagonist used to treat several types of breast cancer, has been shown to induce autophagyassociated cell death by increasing endogenous Cer levels. ${ }^{33}$ Exogenous or endogenous Cer induces autophagy through several mechanisms. For example, Cer has been found to stimulate autophagy by regulating classic or atypical autophagic pathways and signals. ${ }^{4}$ Via these signals, class I PI3K and Akt negatively regulate autophagy, but a class III PI3K is needed for the activation of autophagy. Cer was found to promote the interaction of class III PI3K with other regulators of autophagy ${ }^{38}$ and to inhibit Akt by activating phosphoprotein phosphatase 2A. ${ }^{33,39,40}$ Moreover, exogenously added Cer and the accumulation of endogenous Cer due to treatment with certain chemotherapeutic drugs, such as tamoxifen, inhibit the mTOR signaling pathway, ${ }^{33}$ which has a central role in inducing autophagy and increasing the expression of Beclin1, ${ }^{33}$ an upstream regulator of autophagy. ${ }^{41}$ Simultaneously, Cer promotes the dissociation of Beclin1 from the Beclin1/Bcl-2 complex. ${ }^{34,42,43}$ A short-chain Cer analog has also been associated with the induction of autophagyassociated cell death by increasing the transcription of the BH3-only protein, a mitochondria-associated protein that induces nonapoptotic cell death. ${ }^{35} \mathrm{~A}$ recent study showed that Cer directly interacts with microtubule-associated protein light chain 3 (LC3) on mitochondrial membranes to induce deadly autophagy via an increase in intracellular mitophagy. ${ }^{44}$

S1P has emerged as a cell-proliferative lipid messenger. S1P has been found to induce survival-mediated or protective autophagy under nutrient starvation, distinct from Cerassociated autophagy-associated cell death. ${ }^{45,46}$ In contrast to Cer-related autophagy, S1P-mediated autophagy has not been shown to be related to the accumulation of Beclin1 protein or to the suppression of class I PI3K or Akt. ${ }^{45}$ 
However, mTOR was still inhibited by increased S1P levels, ${ }^{45-47}$ which suggests that S1P induces autophagy via inhibiting mTOR and is independent of the class I PI3K signal.

dhCer has been used as a negative control for Cer treatments to induce autophagy ${ }^{33,34,48}$ because dhCer has long been thought to be biologically inactive. However, dhCer was recently identified as a novel SL-based mediator of autophagy. 3,49,50 dhCer induces both protective autophagy and autophagy-associated cell death. Endogenously added dhCer induced a transient, early increase in dhCer levels via inhibition of dhCer desaturase, such as XM462, which successively promoted autophagy and reduced etoposide toxicity in gastric and colon cancer cells. ${ }^{4,51}$ However, anticancer agents such as fenretinide (4-hydroxy (phenyl) retinamide or $4-\mathrm{HPR})^{50}$ and gamma tocotrienol (a lipophilic antioxidant of vitamin E) ${ }^{52}$ induced cancer cell death through the elevation of intracellular dhCer levels. Interestingly, none of the reported Cer-mediated autophagic pathways is induced by both Cer and dhCer. ${ }^{33}$ Intriguingly, the accumulation of dhCer may serve as an additional 'switch' to regulate cell fate; however, the biological activity of dhCer remains controversial and unclear.

In addition to the major SLs that induce autophagy, gangliosides and several rare SLs are also involved in autophagy-related cell fate decisions. Gangliosides induce autophagy-associated cell death in both isolated astrocytes and astrocytoma cells. ${ }^{53}$ An increase in the amount of LC3-II and an accumulation of autophagic vacuoles were observed in cells that underwent ganglioside treatment. ${ }^{53,54}$ Cer methylaminoethyl phosphonate and sphingadienes are two rare SLs that promote autophagy-associated cell death through the downregulation of PI3K/Akt and the activation of Beclin1, similar to Cer. ${ }^{55,56}$

Overall, although Cer, dhCer, and S1P are all able to induce autophagy, the effects of S1P-mediated autophagy are markedly mild compared with the effects elicited by Cer. dhCer-related autophagic effects are moderate, and their intensity level lies between the levels caused by Cer and S1P. Treatment with chemotherapeutic agents often promotes the biosynthesis of intracellular Cer and leads to autophagyassociated cell death; however, elevation in S1P levels is typically a cell response to nutrition starvation and mediates cytoprotective autophagy. Furthermore, cells maintain a dynamic equilibrium between the levels and the effects of Cer, dhCer, and S1P. The conversion of Cer to S1P simultaneously accumulates the survival effects and removes the death signals. This observation has led to the concept of a so-called 'SL rheostat' or 'SL biostat,' based on the relative amounts and reciprocal roles of these antagonistic metabolites, which are critical in guiding the destiny of cells. ${ }^{12,57,58}$

\section{Possible SL Involvement in the Cross Talk Between Autophagy and Apoptosis}

Apoptosis and autophagy have been recognized as two principal forms of programmed cell death. Apoptosis generally initiates cell death, whereas autophagy is primarily a protective process for the cell that may also contribute to cell death. ${ }^{59}$ There is a sophisticated and not yet fully understood association between autophagy-related cell death and survival that depends on various biological situations. ${ }^{1}$ In certain cellular contexts, autophagy functions as a stress response to suppress apoptosis and promote cell survival. ${ }^{16,60}$ However, in other cases, autophagy may serve as a mechanism for caspase-dependent or -independent cell death. ${ }^{61,62}$

Certain SLs are now thought to elicit autophagy; however, they have also been known to induce apoptosis. Cer is a wellestablished inducer of apoptosis via activation of the mitochondrial pathway. In a number of different cell types, increased Cer levels arrest cell growth and promote cell apoptosis. ${ }^{63-66}$ In contrast to Cer, S1P facilitates cell survival and suppresses cell apoptosis. ${ }^{67-69}$ dhCer has also been suggested to exhibit antiapoptotic effects because the lipid inhibits Cer channel assembly in isolated mitochondria. ${ }^{70}$ In addition, other SL metabolites, such as sphingosine and ganglioside, are involved in the modulation of apoptosis and autophagy. ${ }^{71}$ SL-associated apoptosis and autophagy are interlinked. The conversion of Cer to S1P switches the cell fate from apoptosis to autophagy-induced survival. ${ }^{57,58}$ Several exogenous stimuli, and particularly the activation of the enzymes that interconvert Cer and S1P, such as sphingosine kinases, lead to an increase in S1P levels, a corresponding reduction in Cer levels, and the antagonistic effects of Cer. ${ }^{68}$ In addition, dhCer has been proposed to exhibit antiapoptotic effects to promote cell survival during hypoxia through the induction of autophagy, while also serving as a lipid reserve for the rapid production of Cer to address cellular damage on reperfusion. ${ }^{72}$ dhCer serves as a unique regulator of cell fate, controlling the 'switch' between cytoprotective autophagy and Cer-mediated apoptosis in response to stress. Intriguingly, Cer promotes both apoptosis and autophagy through the inhibition of class I PI3K and Akt signaling or the mTOR pathway. ${ }^{33,40,73,74}$ Furthermore, suppressors of apoptosis, such as the Bcl-2 family, also directly bind and control Beclin1. ${ }^{75}$ Disruption of the Beclin1-Bcl-2 complex has also emerged as a common mechanism in Cer-associated autophagy. ${ }^{71}$ In addition to altering the balance between Beclin1 and Bcl-2 protein levels, endogenous Cer liberates Beclin1 for autophagy induction through the JNK-mediated phosphorylation of $\mathrm{Bcl}-2 .{ }^{34}$ Notably, Bcl-2 has emerged as a critical regulator of the Cer-mediated cross talk between autophagy and apoptosis.

\section{SL-Associated Autophagy and Diseases}

Although the primary function of autophagy is to aid in adaptation to cellular stress under adverse conditions by enabling cells to degrade cytosolic proteins and organelles to generate a supply of essential nutrients, autophagy has also emerged in the pathological process of many disorders, including neurodegeneration, tumors, immunity responses, and heart diseases. ${ }^{16} \mathrm{SL}$ metabolism-associated autophagy also contributes to a range of diseases. ${ }^{31}$

Sphingolipidoses are a collection of more than 40 genetically distinct disorders caused by inherited deficiencies of lysosomal hydrolytic activities or lipid transport. These deficiencies result in intracellular accumulations of cholesterol and lipids in the endosomal/lysosomal network, usually leading to signs of neurodegeneration. ${ }^{76,77}$ The biochemical 
abnormalities in sphingolipidoses are complex and lead to the accumulation of SL metabolites by diverse pathways (Table 1). ${ }^{78,79}$

Niemann-Pick disease type C (NPC) is a complex neurodegenerative sphingolipidosis characterized by the accumulation of unesterified cholesterol, SLs, and complex gangliosides in late endosomes and lysosomes. ${ }^{80}$ The disease is caused by mutations in either the NPC1 or the NPC2 gene, ${ }^{81,82}$ which disturbs not only the regular transport of endocytosed lipids but also the autophagic flux, leading to an accumulation of autophagic vacuoles in cells. ${ }^{83,84}$ NPC1 and $N P C 2^{81,82}$ are genes whose protein products mediate proper intracellular lipid transport through pathways that are incompletely understood. The brains of afflicted humans and NPC-deficient animal models are marked by a loss of neurons. ${ }^{85,86}$ Histological studies and cell culture experiments have shown that defective lysosomal degradation of autophagosomes may contribute to the abnormal autophagic flux. ${ }^{84,87}$ The deficiency present in NPC promotes both the generation of autophagosomes and the impairment of autophagic flux. An imbalance between induction and flux through the autophagic pathway contributes to cell stress and neuronal loss in NPC. ${ }^{77}$

Gaucher disease (GD), a kind of sphingolipidosis, is characterized by the accumulation of glucosylceramide or glucosylsphingosine in the lysosomes of the cells of the monocyte/macrophage system. ${ }^{88,89}$ In GD, the point mutations within the GBA (glucosidase, beta, acid) gene lead to the production of acid $\beta$-glucosidase with functional, kinetic, trafficking, and/or stability defects and a resultant decrease in lysosomal function and increase in the accumulation of glucosylceramide and glucosylsphingosine. ${ }^{76}$ GD can be classed into three subsets, based on the age of onset and the presence of central nervous system abnormalities. Type 1 is known as the non-neuronopathic form, and types 2 and 3 are differentiated from type 1 by neurodegeneration of the central nervous system with either rapid or chronic progression. Vaccaro et al. ${ }^{89}$ reported that mutation of saposin (Sap) $\mathrm{C}$, and not a direct GBA gene mutation, was associated with the type 3 or type 1 phenotype in cases of GD. The decrease in/absence of Sap C affected GCase intracellular localization, resulting in lysosomal lipid accumulation and enhanced

Table 1 SL-associated autophagy in SLs

\begin{tabular}{|c|c|c|c|c|}
\hline Disease & $\begin{array}{l}\text { Gene } \\
\text { mutations }\end{array}$ & $\begin{array}{l}\text { Accumulated SL } \\
\text { substrates }\end{array}$ & $\begin{array}{l}\text { Autophagic } \\
\text { status }\end{array}$ & Ref \\
\hline $\begin{array}{l}\text { Niemann-Pick } \\
\text { disease type C }\end{array}$ & $\begin{array}{l}\text { NPC1 } \\
\text { NPC2 }\end{array}$ & $\begin{array}{l}\text { Sphingomyelin } \\
\text { Glucosylceramide } \\
\text { Lactosylceramide } \\
\text { Sphingosine }\end{array}$ & $\begin{array}{l}\text { Accumulated auto- } \\
\text { phagosomes and } \\
\text { ubiquitinated pro- } \\
\text { teins; impaired } \\
\text { autophagic flux }\end{array}$ & $76-87$ \\
\hline $\begin{array}{l}\text { Gaucher } \\
\text { disease }\end{array}$ & $\begin{array}{l}\text { GBA } \\
\text { Sap C }\end{array}$ & $\begin{array}{l}\text { Glucosylceramide } \\
\text { Glucosylsphingosine }\end{array}$ & $\begin{array}{l}\text { Accumulated auto- } \\
\text { phagosomes and } \\
\text { auto- } \\
\text { phagic substrates; } \\
\text { deficient degrada- } \\
\text { tion } \\
\text { of autolysosome } \\
\text { cargo }\end{array}$ & $76,88-91$ \\
\hline Fabry disease & $G L A$ & Globotriaosylceramide & $\begin{array}{l}\text { Induction of autop- } \\
\text { hagy; impaired } \\
\text { autophagic flux }\end{array}$ & 76,91 \\
\hline
\end{tabular}

Abbreviations: ref, references; SL, sphingolipids autophagy. This study suggested that Sap C might have a role in intralysosomal SL transport, as indicated by the accumulation of glucosylceramide and Cer in the lysosomes of the Sap C-mutant cells. In addition, deficient degradation of autophagic substrates in cells in GD can lead to an increased risk of Parkinson disease. ${ }^{90}$ For NPC, GD, and other sphingolipidoses, ${ }^{76,91}$ the relevance of the impairment of autophagic flux to disease pathogenesis remains poorly defined. In addition, the extent to which the accumulation of autophagic substrates contributes to neuron dysfunction needs to be determined in future studies.

Dysregulated SL metabolism occurs in numerous cancers and has been shown to contribute to cancer progression and chemoresistance. ${ }^{92,93}$ Several species of SLs have been shown to have aberrant expression or metabolism in cancer cells. ${ }^{94}$ The tumor suppressor Cer and the tumor promoter S1P are generally recognized to trigger autophagy; however, Cer and S1P have different outcomes regarding cell death and survival. ${ }^{29}$ Nevertheless, recent studies have suggested that de novo-generated Cer-associated autophagy can be lethal as well as protective for cells. ${ }^{92}$ For example, Beljansky et al. ${ }^{95}$ determined that enhancement of Cer levels through treatment with a SphK 2-selective inhibitor suppresses tumor growth by leading to autophagy-associated cell death. Conversely, Park et al. ${ }^{96}$ suggested that Cer-CD95-PERK signaling promotes cell death via the cascade activation of caspase proteins; however, gene silencing of Atg5 further strengthened the cell death process, indicating that the autophagy was protective. The contradictory activities may correspond to variations among Cers in their carbon chain lengths, double bond numbers, subcellular distributions, and versatile targets. In addition, Cer is metabolized into S1P by SphK 1 or SphK 2, which are associated with protective autophagy and other biological behaviors, including survival, infiltration, angiogenesis, metastasis, and resistance to anticancer drugs in cancer cells. ${ }^{92}$

Intact and impaired SL-related autophagy has significant implications for many other diseases and pathological processes. For example, CerS 5-mediated autophagy has recently been implicated in lipotoxic cardiomyopathy and hypertrophy. ${ }^{97}$ In addition, Kdo 2 -lipid A induced substantial alterations in SL metabolism and composition in RAW264.7 cells, a mouse macrophage-like cell line. These changes apparently promote the de novo SL biosynthesis that is required for autophagosome generation, which is suggested to have an essential role in the processes of the innate immune response. ${ }^{24}$ Cer also mediates the augmentation of interleukin-1(IL-1) levels and the release of tumor necrosis factor (TNF) alpha that are induced by toll-like receptor 4 , and this process may contribute to the enhanced inflammatory response in metabolic diseases, including obesity and diabetes, which are characterized by dyslipidemia. ${ }^{98}$

Overall, the aberrations in the bioactive SLs that mediate autophagy have been associated with diverse pathological conditions, including neurodegeneration, carcinogenesis, metabolic diseases, and inflammatory responses. Understanding the specific mechanism connecting SL-related autophagy and these diseases has substantial implications for revealing these diseases' biochemical characteristics and for designing and developing new therapeutic strategies. 


\section{Compounds and Drugs that Might Trigger Autophagy- Associated Cell Death Through Regulation of SL Metabolism}

Many human disease states may be caused by the aberrant regulation of SL metabolism-associated autophagy; therefore, drugs and compounds that target SL metabolism, including chemotherapeutic drugs, sphingomimetics, and enzyme inhibitors, are attractive candidates for therapeutic development (Table 2).

Many chemotherapeutic drugs elicit autophagy and exert their anticancer properties by increasing the intracellular levels of SLs. A large number of malignant cells often acquire genetic deletions or mutations that render them resistant to the classic apoptotic cell death that is induced by many anticancer therapies, which ultimately results in poor prognosis. ${ }^{99,100}$ In these cases, the use of autophagy-inducing drugs offers an alternative way to induce cell death in apoptosis-resistant tumors. ${ }^{99,100}$ As reviewed in the present paper, one of the major results of the chemotherapy-mediated increase in the levels of intracellular SLs, such as Cer and $\mathrm{dhCer}$, is cell death induction by autophagy in various human cancer cells.

Table 2 Summary of antitumor compounds that might regulate autophagy through SL metabolism

\begin{tabular}{|c|c|c|c|c|c|}
\hline Category & Name & Structure & $\begin{array}{l}\text { Targeted SLs or } \\
\text { enzymes and } \\
\text { related SL side } \\
\text { chains }\end{array}$ & $\begin{array}{l}\text { Autophagic } \\
\text { status }\end{array}$ & Ref \\
\hline \multirow[t]{9}{*}{$\begin{array}{l}\text { Chemo } \\
\text { therapy }\end{array}$} & Tamoxifen & & Cer & $\begin{array}{l}\text { Accumulated } \\
\text { autophagic } \\
\text { Vacuoles }\end{array}$ & 33 \\
\hline & $\begin{array}{l}\text { Arsenic } \\
\text { trioxide }\end{array}$ & $0=A s-0-A s=0$ & Cer & $\begin{array}{l}\text { Increased } \\
\text { autophagy- } \\
\text { associated cell } \\
\text { death }\end{array}$ & 101,102 \\
\hline & $\begin{array}{l}\Delta^{9} \text { - } \\
\text { Tetrahydrocan } \\
\text { nabinol }\end{array}$ & & Cer & $\begin{array}{l}\text { Increased number } \\
\text { of } \\
\text { autophagosomes }\end{array}$ & 103 \\
\hline & Etoposide & & SphK/Cer & $\begin{array}{l}\text { Accumulated } \\
\text { autophagosomes/ } \\
\text { autolysosomes }\end{array}$ & 61,104 \\
\hline & Doxorubicin & & SphK & $\begin{array}{l}\text { Switch from } \\
\text { protective } \\
\text { autophagy } \\
\text { to apoptosis }\end{array}$ & 105 \\
\hline & Daunorubicin & & SMase & $\begin{array}{l}\text { Induction of a } \\
\text { high level of } \\
\text { protective } \\
\text { autophagy }\end{array}$ & 106,107 \\
\hline & Resveratrol & & $\underset{(\mathrm{C} 16-\mathrm{dhCer})}{\mathrm{dhCer}}$ & $\begin{array}{l}\text { Accumulated } \\
\text { vesicles } \\
\text { with distinct } \\
\text { double } \\
\text { membranes }\end{array}$ & 49,108 \\
\hline & 4-HPR & & $\underbrace{\mathrm{dhCer}}_{(\mathrm{C} 16-\mathrm{dhCer})}$ & $\begin{array}{l}\text { Increased } \\
\text { numbers of } \\
\text { lysosomes/ } \\
\text { autophagosomes }\end{array}$ & $\begin{array}{l}52, \\
109-112\end{array}$ \\
\hline & & & 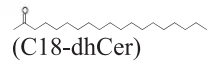 & & \\
\hline
\end{tabular}




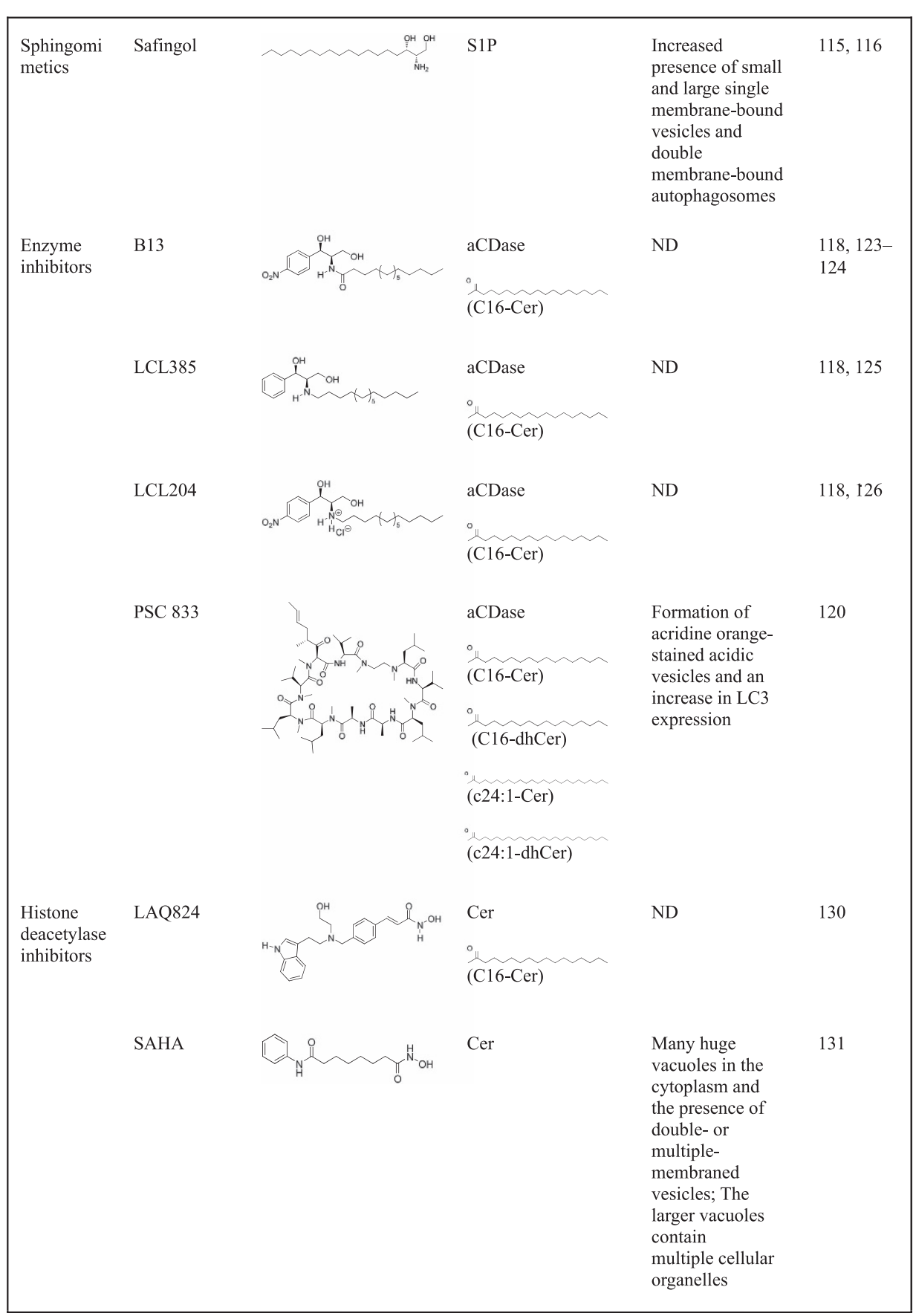

Abbreviations: ND, not determined; ref, reference; SL, sphingolipids

Autophagy is initiated by tamoxifen, an antagonist of the estrogen receptor, leading to an increase in endogenous Cer levels that acts against breast cancer cells. ${ }^{33}$ Arsenic trioxide, a potent antineoplastic agent, has been used clinically for the treatment of certain types of leukemia. Arsenic trioxide was shown to induce the biosynthesis of Cer in both acute promyelocytic leukemia and adult T-cell leukemia cells, and the cytotoxic effects were attributed to the induction of both apoptosis and autophagy. ${ }^{101,102} \Delta^{9}$-Tetrahydrocannabinol, the major active component of marijuana, was reported to induce the activation of autophagy-mediated apoptotic cell death by increasing de novo Cer biosynthesis. ${ }^{103}$ Moreover, SL metabolism may be involved in the regulation of autophagy by other chemotherapeutic drugs, including, but not limited to, etoposide, ${ }^{61,104}$ doxorubicin, ${ }^{105}$ and daunorubicin. ${ }^{106,107}$

Resveratrol is a natural polyphenolic phytoalexin produced by grapes and other berries that exerts its cancer-preventive properties in several animal models and exhibits its potent 
anticancer activities in leukemia and many solid tumors. The capacity to trigger dhCer biosynthesis contributes to resveratrol-induced autophagy-associated cell death. Puissant et al. ${ }^{108}$ found that resveratrol initiates autophagy in chronic myelogenous leukemia cells through the AMP-activated protein kinase (AMPK)-dependent induction of autophagy and that p62 is also required for resveratrol-mediated autophagy. Whether other polyphenolic compounds, such as curcumin, which has two phenolic hydroxyl groups: genistein, which has three phenolic hydroxyl groups; and quercetin, which has four phenolic hydroxyl groups, are implicated in SL metabolism and SL-mediated autophagy remains to be determined.

In clinical trials, 4-HPR has been encouraging as a chemopreventive and therapeutic agent for breast cancer. ${ }^{109,110}$ The promise of 4 -HPR as a therapeutic agent is enhanced by its unique ability to activate the autophagyassociated cell death pathway when the apoptotic pathway is deregulated, which is a characteristic that is not shared by other chemotherapeutic agents, including cisplatin and etoposide. ${ }^{109}$ Furthermore, the accumulation of dhCer following treatment with 4-HPR was found to induce cell cycle arrest in neuroblastoma cells. ${ }^{111,112}$

SL metabolism is an exploitable target for the discovery of novel chemotherapeutics, and this target has been validated through the development of several sphingomimetics. ${ }^{8,113,114}$ Safingol, a synthetic sphinganine, triggers autophagy in several tumor cell types by the suppression of class I PI3K and Akt signaling. ${ }^{115}$ Safingol has been assessed in phase I clinical trials alone or in combination with cisplatin for adults with advanced solid tumors and for children with neuroblastoma. Safingol treatment was shown to trigger a dosedependent decrease in S1P levels, and safingol is a promising representative drug whose primary mechanism for promoting tumor cell death is autophagy. ${ }^{116}$

Targeting enzymes in SL metabolism is another attractive avenue to provide therapeutic benefits in SL-related human diseases. ${ }^{117,118}$ Acid SMases (aSMases) and acid ceramidases (aCDases) are crucial enzymes that modulate the synthesis and degradation of Cer in SL metabolism.2,6 aCDase overexpression has been observed in cancer cell lines and primary tumors and contributes to resistance to chemotherapy and radiation. ${ }^{119-121}$ The consequence of aCDase overexpression is the ability to convert Cer, which is often produced as a proapoptotic response to stress, to sphingosine, which can then be converted to S1P. ${ }^{122}$ In addition to the ability to metabolize the Cer produced in response to stress, Turner et al. ${ }^{119}$ found that prostate cancer cell lines overexpressing aCDase also have an increased lysosomal density and increased levels of autophagy. Morad et al. $^{120}$ identified an analog of cyclosporin A, PSC 833 (Valspodar, Novartis Pharma AG, Basel, Switzerland), a second-generation, non-immunosuppressive P-glycoprotein antagonist that inhibits aCDase and generates autophagyassociated cytotoxicity in pancreatic cancer cells. B13 was found to be a potent CDase inhibitor that induced colon cancer cell death ${ }^{123}$ and the inhibition of colon tumor growth in a xenograft model. ${ }^{124}$ Furthermore, LCL385, a B13 analog, enhanced the sensitivity of prostate cancer cells to radiation and inhibited tumor growth in a nude mouse model. ${ }^{125}$
Another novel B13 analog, LCL204, has been shown to overcome the resistance of head and neck squamous carcinoma cells to Fas-induced cell death in both in vitro and in vivo experiments. ${ }^{126}$ Most aCDase inhibitors are lysosomotropic agents and cause lysosomal destabilization and a change in SL metabolism enzymes in the lysosomal compartment. ${ }^{118}$

aSMase hydrolyzes sphingomyelin into Cer and phosphorylcholine. For the most part, aSMase seems to reside in classic lysosomes, where it mediates the catabolism of sphingomyelin. ${ }^{117}$ aSMase activity is essential for lysosomal stability and the survival of cancer cells, as well as for the multidrug-resistant phenotype. Because of their ability to inhibit autophagic flux, certain aSMase inhibitors, such as chloroquine, siramesine, and clomipramine, are currently being tested as anticancer agents in several clinical trials and laboratory studies. ${ }^{127}$ aSMase was also found to be a target for the treatment of Niemann-Pick disease type A (NPA), which is caused by loss-of-function mutations in the aSMase gene and is a lysosomal storage disorder leading to neurodegeneration. Fibroblasts from NPA patients and aSMase-knockout mouse brains show similar autophagolysosome accumulation and impaired autophagy. ${ }^{128} \mathrm{~A}$ recent study has suggested that the control of lysosome trafficking and fusion by aSMase is essential to normal autophagic flux in coronary arterial smooth muscle cells and has a protective role in atherosclerosis. ${ }^{129}$

Other chemotherapeutic treatments, such as several histone deacetylase inhibitors, were also demonstrated to lead to leukemic cell death by enhancing Cer production via the degradation of sphingomyelin. ${ }^{130}$ One of these histone deacetylase inhibitors is suberoylanilide hydroxamic acid, which was demonstrated to trigger autophagy-associated cell death in apoptosis-deficient tumor cells, such as chondrosarcoma cells. ${ }^{131}$

\section{Conclusion}

Numerous well-developed and convenient experimental methods and techniques that can be used to detect autophagy in different species systems exist. ${ }^{132,133}$ To establish that an autophagic response is occurring in SL-related autophagy, multiple methods have been used, including cellular ultrastructure studies by transmission electron microscopy, ${ }^{132,133}$ an LC3-puncta formation assay combined with immunoblots for autophagic cargoes (for example, p62 and NBR1), and the detection of autophagy-related molecules. ${ }^{132,134}$ In addition, performing a large-scale and comprehensive sphingolipidomic analysis has been challenging in the study of SLassociated autophagy. ${ }^{135,136}$ Both nets and hooks are indispensable tools to allow efficient 'fishing' for multiple intermediates and products directly from the sophisticated process of SL metabolism.

Because there is an obvious overlap between the subcellular localization of enzymes needed for SL biosynthesis and autophagosome formation, SLs have been increasingly implicated in the composition of the phagophore and the autophagosomal membrane.

Autophagy-associated cell death and cell survival represent the so-called 'Yin-Yang' regulatory mechanism. The balance 
has been exemplified by interconvertible SLs that produce opposite autophagic effects on cells that were termed as 'SL rheostat' or 'SL biostat'. In addition, the increase in intracellular Cer levels usually results from chemotherapy and often stimulates autophagy-associated cell death, although this increase has also been found to be cytoprotective. In contrast, starvation treatment triggers protective autophagy via increasing S1P levels. However, the underlying mechanisms by which chemotherapy and nutrient deprivation mediate different regulation are still largely unknown.

In addition to autophagy, SLs have long been identified to induce apoptosis. SLs mediate the cross talk between apoptosis and autophagy because certain SLs share several common kinase signaling pathways that regulate cell fate that affect both apoptosis and autophagy or execute a seesaw type of regulation of key molecules.

Increasing new knowledge on the biochemistry and cell biology of SL-mediated autophagy is beneficial for deepening our understanding of SL-associated diseases, including neurodegeneration, cancer pathogenesis, and inflammatory responses. An imbalance between induction of and flux through the autophagic pathway contributes to cell stress and neuronal loss in NPC. Intact and impaired SL-related autophagy has significant implications for the development of malignant tumors.

In addition, the current understanding of the effects of multiple SLs on the modulation of various autophagy-related cell fates has primarily arisen from exogenous SLs or pharmacological perturbations of SL metabolism. The identification of SL-mediated cytoprotective autophagy that can be shifted to cell death may provide a novel strategy for cancer therapy, including chemotherapy, sphingomimetics, SL metabolic enzyme inhibitors, and histone deacetylase inhibitors.

\section{Conflict of Interest}

The authors declare no conflict of interest.

Acknowledgements. This work was supported by the National Natural Science Foundation of China, Grants 81100764, 81172287, 81202139, and 81230043.

1. Levine B. Cell biology: autophagy and cancer. Nature 2007; 446: 745-747.

2. Hla T, Dannenberg AJ. Sphingolipid signaling in metabolic disorders. Cell Metab 2012; 16: $420-434$.

3. Zheng W, Kollmeyer J, Symolon H, Momin A, Munter E, Wang E et al. Ceramides and other bioactive sphingolipid backbones in health and disease: lipidomic analysis, metabolism and roles in membrane structure, dynamics, signaling and autophagy. Biochim Biophys Acta 2006; 1758: 1864-1884.

4. Bedia C, Levade T, Codogno P. Regulation of autophagy by sphingolipids. Anticancer Agents Med Chem 2011; 11: 844-853.

5. Bartke N, Hannun YA. Bioactive sphingolipids: metabolism and function. $J$ Lipid Res 2009; 50(Suppl): S91-S96.

6. Hannun YA, Obeid LM. Principles of bioactive lipid signalling: lessons from sphingolipids. Nat Rev Mol Cell Biol 2008; 9: 139-150.

7. Becker KP, Kitatani K, Idkowiak-Baldys J, Bielawski J, Hannun YA. Selective inhibition of juxtanuclear translocation of protein kinase $C$ betall by a negative feedback mechanism involving ceramide formed from the salvage pathway. J Biol Chem 2005; 280: 2606-2612.

8. Merrill Jr AH. Sphingolipid and glycosphingolipid metabolic pathways in the era of sphingolipidomics. Chem Rev 2011; 111: 6387-6422.

9. van Meer G, Lisman Q. Sphingolipid transport: rafts and translocators. J Biol Chem 2002; 277: 25855-25858

10. Futerman $\mathrm{AH}$. Intracellular trafficking of sphingolipids: relationship to biosynthesis. Biochim Biophys Acta 2006; 1758: 1885-1892.
11. Gault CR, Obeid LM, Hannun YA. An overview of sphingolipid metabolism: from synthesis to breakdown. Adv Exp Med Biol 2010; 688: 1-23.

12. Dall'Armi C, Devereaux KA, Di Paolo G. The role of lipids in the control of autophagy. Curr Biol 2013; 23: R33-R45.

13. Yorimitsu T, Klionsky DJ. Autophagy: molecular machinery for self-eating. Cell Death Differ 2005; 12(Suppl 2): 1542-1552.

14. Mizushima N. Autophagy: process and function. Genes Dev 2007; 21: 2861-2873.

15. Barth S, Glick D, Macleod KF. Autophagy: assays and artifacts. J Pathol 2010; 221: 117-124.

16. Mizushima N, Levine B, Cuervo AM, Klionsky DJ. Autophagy fights disease through cellular self-digestion. Nature 2008; 451: 1069-1075.

17. Mizushima N, Komatsu M. Autophagy: renovation of cells and tissues. Cell 2011; 147: 728-741.

18. Tanida I. Autophagy basics. Microbiol Immunol 2011; 55: 1-11.

19. Klionsky DJ, Codogno P, Cuervo AM, Deretic V, Elazar Z, Fueyo-Margareto J et al. A comprehensive glossary of autophagy-related molecules and processes. Autophagy 2010; 6: 438-448.

20. Klionsky DJ, Baehrecke EH, Brumell JH, Chu CT, Codogno P, Cuervo AM et al. A comprehensive glossary of autophagy-related molecules and processes (2nd edition). Autophagy 2011; 7: 1273-1294.

21. Grassme H, Riethmuller J, Gulbins E. Biological aspects of ceramide-enriched membrane domains. Prog Lipid Res 2007; 46: 161-170.

22. Schenck M, Carpinteiro A, Grassme H, Lang F, Gulbins E. Ceramide: physiological and pathophysiological aspects. Arch Biochem Biophys 2007; 462: 171-175.

23. Yamagata M, Obara K, Kihara A. Sphingolipid synthesis is involved in autophagy in Saccharomyces cerevisiae. Biochem Biophys Res Commun 2011; 410: 786-791.

24. Sims K, Haynes CA, Kelly S, Allegood JC, Wang E, Momin A et al. Kdo2-lipid A, a TLR4specific agonist, induces de novo sphingolipid biosynthesis in RAW264.7 macrophages, which is essential for induction of autophagy. J Biol Chem 2010; 285: 38568-38579.

25. Yamashita S, Oku M, Wasada Y, Ano Y, Sakai Y. PI4P-signaling pathway for the synthesis of a nascent membrane structure in selective autophagy. J Cell Biol 2006; 173: 709-717.

26. Mandon EC, Ehses I, Rother J, van Echten G, Sandhoff K. Subcellular localization and membrane topology of serine palmitoyltransferase, 3-dehydrosphinganine reductase, and sphinganine N-acyltransferase in mouse liver. J Biol Chem 1992; 267: 11144-11148.

27. Hosokawa N, Hara T, Kaizuka T, Kishi C, Takamura A, Miura Y et al. Nutrient-dependent mTORC1 association with the ULK1-Atg13-FIP200 complex required for autophagy. Mol Biol Cell 2009; 20: 1981-1991.

28. Chan EY. mTORC1 phosphorylates the ULK1-mAtg13-FIP200 autophagy regulatory complex. Sci Signal 2009; 2: pe51.

29. Ogretmen B, Hannun YA. Biologically active sphingolipids in cancer pathogenesis and treatment. Nat Rev Cancer 2004; 4: 604-616.

30. Suzuki E, Handa K, Toledo MS, Hakomori S. Sphingosine-dependent apoptosis: a unified concept based on multiple mechanisms operating in concert. Proc Natl Acad Sci USA 2004; 101: 14788-14793.

31. Ravikumar B, Sarkar S, Davies JE, Futter M, Garcia-Arencibia M, Green-Thompson ZW et al. Regulation of mammalian autophagy in physiology and pathophysiology. Physiol Rev 2010; 90: 1383-1435.

32. Saddoughi SA, Song P, Ogretmen B. Roles of bioactive sphingolipids in cancer biology and therapeutics. Subcell Biochem 2008; 49: 413-440.

33. Scarlatti F, Bauvy C, Ventruti A, Sala G, Cluzeaud F, Vandewalle A et al. Ceramidemediated macroautophagy involves inhibition of protein kinase $B$ and up-regulation of beclin 1. J Biol Chem 2004; 279: 18384-18391.

34. Pattingre S, Bauvy C, Carpentier S, Levade T, Levine B, Codogno P. Role of JNK1dependent $\mathrm{Bcl}-2$ phosphorylation in ceramide-induced macroautophagy. $\mathrm{J}$ Biol Chem 2009; 284: 2719-2728.

35. Daido S, Kanzawa T, Yamamoto A, Takeuchi H, Kondo Y, Kondo S. Pivotal role of the cell death factor BNIP3 in ceramide-induced autophagic cell death in malignant glioma cells. Cancer Res 2004; 64: 4286-4293.

36. Aoki H, Kondo Y, Aldape K, Yamamoto A, Iwado E, Yokoyama T et al. Monitoring autophagy in glioblastoma with antibody against isoform $B$ of human microtubuleassociated protein 1 light chain 3. Autophagy 2008; 4: 467-475.

37. Sun T, Li D, Wang L, Xia L, Ma J, Guan Z et al. c-Jun NH2-terminal kinase activation is essential for up-regulation of LC3 during ceramide-induced autophagy in human nasopharyngeal carcinoma cells. J Transl Med 2011; 9: 161.

38. Zeng X, Overmeyer JH, Maltese WA. Functional specificity of the mammalian BeclinVps34 PI 3-kinase complex in macroautophagy versus endocytosis and lysosomal enzyme trafficking. J Cell Sci 2006; 119(Pt 2): 259-270.

39. Schubert KM, Scheid MP, Duronio V. Ceramide inhibits protein kinase B/Akt by promoting dephosphorylation of serine 473. J Biol Chem 2000; 275: 13330-13335.

40. Zhou H, Summers SA, Birnbaum MJ, Pittman RN. Inhibition of Akt kinase by cellpermeable ceramide and its implications for ceramide-induced apoptosis. $\mathrm{J}$ Biol Chem 1998; 273: 16568-16575.

41. Kanzawa T, Zhang L, Xiao L, Germano IM, Kondo Y, Kondo S. Arsenic trioxide induces autophagic cell death in malignant glioma cells by upregulation of mitochondrial cell death protein BNIP3. Oncogene 2005; 24: 980-991.

42. Cao Y, Klionsky DJ. Physiological functions of Atg6/Beclin 1: a unique autophagy-related protein. Cell Res 2007; 17: 839-849. 
43. Walker T, Mitchell C, Park MA, Yacoub A, Graf M, Rahmani M et al. Sorafenib and vorinostat kill colon cancer cells by CD95-dependent and -independent mechanisms. $\mathrm{Mol}$ Pharmacol 2009; 76: 342-355.

44. Sentelle RD, Senkal CE, Jiang W, Ponnusamy S, Gencer S, Selvam SP et al. Ceramide targets autophagosomes to mitochondria and induces lethal mitophagy. Nat Chem Biol 2012; 8: 831-838.

45. Lavieu G, Scarlatti F, Sala G, Carpentier S, Levade T, Ghidoni R et al. Regulation of autophagy by sphingosine kinase 1 and its role in cell survival during nutrient starvation. J Biol Chem 2006; 281: 8518-8527.

46. Oskouian B, Saba JD. Cancer treatment strategies targeting sphingolipid metabolism. Adv Exp Med Biol 2010; 688: 185-205

47. Chang $\mathrm{CL}$, Ho MC, Lee PH, Hsu CY, Huang WP, Lee H. S1P(5) is required for sphingosine 1-phosphate-induced autophagy in human prostate cancer PC-3 cells. Am J Physiol Cell Physiol 2009; 297: C451-C458.

48. Li DD, Wang LL, Deng R, Tang J, Shen Y, Guo JF et al. The pivotal role of c-Jun $\mathrm{NH} 2$-terminal kinase-mediated Beclin 1 expression during anticancer agents-induced autophagy in cancer cells. Oncogene 2009; 28: 886-898.

49. Signorelli P, Munoz-Olaya JM, Gagliostro V, Casas J, Ghidoni R, Fabrias G. Dihydroceramide intracellular increase in response to resveratrol treatment mediates autophagy in gastric cancer cells. Cancer Lett 2009; 282: 238-243.

50. Jiang $Q$, Rao X, Kim CY, Freiser H, Zhang Q, Jiang Z et al. Gamma-tocotrienol induces apoptosis and autophagy in prostate cancer cells by increasing intracellular dihydrosphingosine and dihydroceramide. Int J Cancer 2012; 130: 685-693.

51. Gagliostro V, Casas J, Caretti A, Abad JL, Tagliavacca L, Ghidoni R et al. Dihydroceramide delays cell cycle G1/S transition via activation of ER stress and induction of autophagy. Int J Biochem Cell Biol 2012; 44: 2135-2143.

52. Wang H, Maurer BJ, Liu YY, Wang E, Allegood JC, Kelly $S$ et al. $\mathrm{N}$-(4-Hydroxyphenyl)retinamide increases dihydroceramide and synergizes with dimethylsphingosine to enhance cancer cell killing. Mol Cancer Ther 2008; 7: 2967-2976.

53. Hwang J, Lee S, Lee JT, Kwon TK, Kim DR, Kim H et al. Gangliosides induce autophagic cell death in astrocytes. Br J Pharmacol 2010; 159: 586-603.

54. Hwang J, Lee HJ, Lee WH, Suk K. NF-kappaB as a common signaling pathway in ganglioside-induced autophagic cell death and activation of astrocytes. J Neuroimmuno 2010; 226: 66-72

55. Chintalapati M, Truax R, Stout R, Portier R, Losso JN. In vitro and in vivo anti-angiogenic activities and inhibition of hormone-dependent and -independent breast cancer cells by ceramide methylaminoethylphosphonate. J Agric Food Chem 2009; 57: 5201-5210.

56. Fyrst $\mathrm{H}$, Oskouian B, Bandhuvula $\mathrm{P}$, Gong $\mathrm{Y}$, Byun HS, Bittman $\mathrm{R}$ et al. Natural sphingadienes inhibit Akt-dependent signaling and prevent intestinal tumorigenesis. Cancer Res 2009; 69: 9457-9464.

57. Cuvillier O, Pirianov G, Kleuser B, Vanek PG, Coso OA, Gutkind S et al. Suppression of ceramide-mediated programmed cell death by sphingosine-1-phosphate. Nature 1996; 381: 800-803.

58. Van Brocklyn JR, Williams JB. The control of the balance between ceramide and sphingosine-1-phosphate by sphingosine kinase: oxidative stress and the seesaw of cell survival and death. Comp Biochem Physiol B Biochem Mol Biol 2012; 163: 26-36.

59. Maiuri MC, Zalckvar E, Kimchi A, Kroemer G. Self-eating and self-killing: crosstalk between autophagy and apoptosis. Nat Rev Mol Cell Biol 2007; 8: 741-752.

60. Kroemer G, Marino G, Levine B. Autophagy and the integrated stress response. Mol Cell 2010; 40: 280-293

61. Shimizu S, Kanaseki T, Mizushima N, Mizuta T, Arakawa-Kobayashi S, Thompson CB et al. Role of Bcl-2 family proteins in a non-apoptotic programmed cell death dependent on autophagy genes. Nat Cell Biol 2004; 6: 1221-1228.

62. Yu L, Alva A, Su H, Dutt P, Freundt E, Welsh $S$ et al. Regulation of an ATG7-beclin 1 program of autophagic cell death by caspase-8. Science 2004; 304: 1500-1502.

63. Hannun YA, Luberto C. Ceramide in the eukaryotic stress response. Trends Cell Bio 2000; 10: 73-80.

64. Kolesnick R, Hannun YA. Ceramide and apoptosis. Trends Biochem Sci 1999; 24 224-225; author reply 227.

65. Levade T, Jaffrezou JP. Signalling sphingomyelinases: which, where, how and why? Biochim Biophys Acta 1999; 1438: 1-17.

66. Mathias S, Pena LA, Kolesnick RN. Signal transduction of stress via ceramide. Biochem J 1998; 335(Pt 3): 465-480.

67. Pyne S, Pyne NJ. Sphingosine 1-phosphate signalling in mammalian cells. Biochem J 2000; 349(Pt 2): 385-402.

68. Spiegel S, Milstien S. Sphingosine-1-phosphate: an enigmatic signalling lipid. Nat Rev Mol Cell Biol 2003; 4: 397-407.

69. Spiegel S, Milstien S. Sphingosine-1-phosphate: signaling inside and out. FEBS Lett 2000; 476: 55-57.

70. Stiban J, Fistere D, Colombini M. Dihydroceramide hinders ceramide channel formation: implications on apoptosis. Apoptosis 2006; 11: 773-780.

71. Young MM, Kester M, Wang HG. Sphingolipids: regulators of crosstalk between apoptosis and autophagy. J Lipid Res 2013; 54: 5-19.

72. Devlin CM, Lahm T, Hubbard WC, Van Demark M, Wang KC, Wu X et al. Dihydroceramide-based response to hypoxia. J Biol Chem 2011; 286: 38069-38078.

73. Yu T, Li J, Qiu Y, Sun H. 1-phenyl-2-decanoylamino-3-morpholino-1-propanol (PDMP) facilitates curcumin-induced melanoma cell apoptosis by enhancing ceramide accumulation, JNK activation, and inhibiting PI3K/AKT activation. Mol Cell Biochem 2012; 361: 47-54.

74. Taniguchi M, Kitatani K, Kondo T, Hashimoto-Nishimura M, Asano S, Hayashi A et al. Regulation of autophagy and its associated cell death by 'sphingolipid rheostat': reciprocal role of ceramide and sphingosine 1-phosphate in the mammalian target of rapamycin pathway. J Biol Chem 2012; 287: 39898-39910.

75. Pattingre S, Tassa A, Qu X, Garuti R, Liang XH, Mizushima N et al. Bcl-2 antiapoptotic proteins inhibit Beclin 1-dependent autophagy. Cell 2005; 122: 927-939.

76. Lieberman AP, Puertollano R, Raben N, Slaugenhaupt S, Walkley SU, Ballabio A. Autophagy in lysosomal storage disorders. Autophagy 2012; 8: 719-730.

77. Pacheco CD, Lieberman AP. The pathogenesis of Niemann-Pick type $C$ disease: a role for autophagy? Expert Rev Mol Med 2008; 10: e26.

78. Eckhardt M. Pathology and current treatment of neurodegenerative sphingolipidoses. Neuromolecular Med 2010; 12: 362-382.

79. Staretz-Chacham O, Lang TC, LaMarca ME, Krasnewich D, Sidransky E. Lysosomal storage disorders in the newborn. Pediatrics 2009; 123: 1191-1207.

80. Karten B, Peake KB, Vance JE. Mechanisms and consequences of impaired lipid trafficking in Niemann-Pick type C1-deficient mammalian cells. Biochim Biophys Acta 2009; 1791: 659-670.

81. Carstea ED, Morris JA, Coleman KG, Loftus SK, Zhang D, Cummings $C$ et al. NiemannPick C1 disease gene: homology to mediators of cholesterol homeostasis. Science 1997; 277: 228-231.

82. Naureckiene $\mathrm{S}$, Sleat DE, Lackland $\mathrm{H}$, Fensom A, Vanier MT, Wattiaux $\mathrm{R}$ et al. Identification of HE1 as the second gene of Niemann-Pick C disease. Science 2000; 290: 2298-2301.

83. Elrick MJ, Yu T, Chung C, Lieberman AP. Impaired proteolysis underlies autophagic dysfunction in Niemann-Pick type C disease. Human Mol Genet 2012; 21: 4876-4887.

84. Ishibashi S, Yamazaki T, Okamoto K. Association of autophagy with cholesterolaccumulated compartments in Niemann-Pick disease type C cells. J Clin Neurosci2009; 16: 954-959.

85. Walterfang M, Fahey M, Desmond P, Wood A, Seal ML, Steward C et al. White and gray matter alterations in adults with Niemann-Pick disease type C: a cross-sectional study. Neurology 2010; 75: 49-56.

86. Yamada A, Saji M, Ukita Y, Shinoda Y, Taniguchi M, Higaki K et al. Progressive neuronal loss in the ventral posterior lateral and medial nuclei of thalamus in Niemann-Pick disease type C mouse brain. Brain Dev 2001; 23: 288-297.

87. Liao G, Yao Y, Liu J, Yu Z, Cheung S, Xie A et al. Cholesterol accumulation is associated with lysosomal dysfunction and autophagic stress in Npc1 -/- mouse brain. Am J Pathol 2007; 171: 962-975.

88. Grabowski GA. Gaucher disease and other storage disorders. Hematology Am Soc Hematol Educ Program 2012; 2012: 13-18.

89. Vaccaro AM, Motta M, Tatti M, Scarpa S, Masuelli L, Bhat M et al. Saposin C mutations in Gaucher disease patients resulting in lysosomal lipid accumulation, saposin C deficiency, but normal prosaposin processing and sorting. Human Mol Genet 2010; 19: 2987-2997.

90. Mazzulli JR, Xu YH, Sun Y, Knight AL, McLean PJ, Caldwell GA et al. Gaucher disease glucocerebrosidase and alpha-synuclein form a bidirectional pathogenic loop in synucleinopathies. Cell 2011; 146: 37-52.

91. Chevrier M, Brakch N, Celine L, Genty D, Ramdani Y, Moll S et al. Autophagosome maturation is impaired in Fabry disease. Autophagy 2010; 6: 589-599.

92. Ponnusamy S, Meyers-Needham M, Senkal CE, Saddoughi SA, Sentelle D, Selvam SP et al. Sphingolipids and cancer: ceramide and sphingosine-1-phosphate in the regulation of cell death and drug resistance. Future Oncol 2010; 6: 1603-1624.

93. Morad SA, Cabot MC. Ceramide-orchestrated signalling in cancer cells. Nat Rev Cancer 2013; 13: 51-65

94. Hakomori S. Glycosylation defining cancer malignancy: new wine in an old bottle. Proc Natl Acad Sci USA 2002; 99: 10231-10233.

95. Beljanski V, Knaak C, Smith CD. A novel sphingosine kinase inhibitor induces autophagy in tumor cells. J Pharmacol Exp Ther 2010; 333: 454-464.

96. Park MA, Zhang G, Norris J, Hylemon PB, Fisher PB, Grant $S$ et al. Regulation of autophagy by ceramide-CD95-PERK signaling. Autophagy 2008; 4: 929-931.

97. Russo SB, Baicu CF, Van Laer A, Geng T, Kasiganesan H, Zile MR et al. Ceramide synthase 5 mediates lipid-induced autophagy and hypertrophy in cardiomyocytes. J Clin Invest 2012; 122: 3919-3930.

98. Schilling JD, Machkovech HM, He L, Sidhu R, Fujiwara H, Weber K et al. Palmitate and lipopolysaccharide trigger synergistic ceramide production in primary macrophages. J Biol Chem 2013; 288: 2923-2932.

99. Eisenberg-Lerner A, Kimchi A. The paradox of autophagy and its implication in cancer etiology and therapy. Apoptosis 2009; 14: 376-391.

100. Schleicher SM, Moretti L, Varki V, Lu B. Progress in the unraveling of the endoplasmic reticulum stress/autophagy pathway and cancer: implications for future therapeutic approaches. Drug Resist Updat 2010; 13: 79-86.

101. Dbaibo GS, Kfoury Y, Darwiche N, Panjarian S, Kozhaya L, Nasr R et al. Arsenic trioxide induces accumulation of cytotoxic levels of ceramide in acute promyelocytic leukemia and adult T-cell leukemia/lymphoma cells through de novo ceramide synthesis and inhibition of glucosylceramide synthase activity. Haematologica 2007; 92: 753-762. 
102. Qian W, Liu J, Jin J, Ni W, Xu W. Arsenic trioxide induces not only apoptosis but also autophagic cell death in leukemia cell lines via up-regulation of Beclin-1. Leuk Res 2007 31: 329-339.

103. Salazar M, Carracedo A, Salanueva IJ, Hernandez-Tiedra S, Lorente M, Egia A et al. Cannabinoid action induces autophagy-mediated cell death through stimulation of ER stress in human glioma cells. J Clin Invest 2009; 119: 1359-1372.

104. Bonhoure E, Pchejetski D, Aouali N, Morjani H, Levade T, Kohama T et al. Overcoming MDR-associated chemoresistance in $\mathrm{HL}-60$ acute myeloid leukemia cells by targeting sphingosine kinase-1. Leukemia 2006; 20: 95-102.

105. Lepine S, Allegood JC, Edmonds Y, Milstien S, Spiegel S. Autophagy induced by deficiency of sphingosine-1-phosphate phosphohydrolase 1 is switched to apoptosis by calpain-mediated autophagy-related gene 5 (Atg5) cleavage. J Biol Chem 2011; 286: 44380-44390.

106. Han W, Sun J, Feng L, Wang K, Li D, Pan $Q$ et al. Autophagy inhibition enhances daunorubicin-induced apoptosis in K562 cells. PLoS One 2011; 6: e28491.

107. Jaffrezou JP, Levade T, Bettaieb A, Andrieu N, Bezombes C, Maestre N et al. Daunorubicin-induced apoptosis: triggering of ceramide generation through sphingomyelin hydrolysis. EMBO J 1996; 15: 2417-2424.

108. Puissant A, Robert G, Fenouille N, Luciano F, Cassuto JP, Raynaud S et al. Resveratro promotes autophagic cell death in chronic myelogenous leukemia cells via JNK-mediated p62/SQSTM1 expression and AMPK activation. Cancer Res 2010; 70: 1042-1052.

109. Fazi B, Bursch W, Fimia GM, Nardacci R, Piacentini M, Di Sano F et al. Fenretinide induces autophagic cell death in caspase-defective breast cancer cells. Autophagy 2008; 4: $435-441$.

110. Sogno I, Vene R, Ferrari N, De Censi A, Imperatori A, Noonan DM et al. Angioprevention with fenretinide: targeting angiogenesis in prevention and therapeutic strategies. Crit Rev Oncol Hematol 2010; 75: 2-14.

111. Kraveka JM, Li L, Szulc ZM, Bielawski J, Ogretmen B, Hannun YA et al. Involvement of dihydroceramide desaturase in cell cycle progression in human neuroblastoma cells J Biol Chem 2007; 282: 16718-16728.

112. Ryland LK, Fox TE, Liu X, Loughran TP, Kester M. Dysregulation of sphingolipid metabolism in cancer. Cancer Biol Ther 2011; 11: 138-149.

113. Barth BM, Cabot MC, Kester M. Ceramide-based therapeutics for the treatment of cancer. Anticancer Agents Med Chem 2011; 11: 911-919.

114. Kester M, Kolesnick R. Sphingolipids as therapeutics. Pharmacol Res 2003; 47: 365-371.

115. Coward J, Ambrosini G, Musi E, Truman JP, Haimovitz-Friedman A, Allegood JC et al. Safingol (L-threo-sphinganine) induces autophagy in solid tumor cells through inhibition of PKC and the PI3-kinase pathway. Autophagy 2009; 5: 184-193.

116. Dickson MA, Carvajal RD, Merrill Jr AH, Gonen M, Cane LM, Schwartz GK. A phase clinical trial of safingol in combination with cisplatin in advanced solid tumors. Clin Cance Res 2011; 17: 2484-2492.

117. Canals D, Perry DM, Jenkins RW, Hannun YA. Drug targeting of sphingolipid metabolism: sphingomyelinases and ceramidases. Br J Pharmacol 2011; 163: 694-712.

118. Bielawska A, Bielawski J, Szulc ZM, Mayroo N, Liu X, Bai A et al. Novel analogs of D-eMAPP and B13. Part 2: signature effects on bioactive sphingolipids. Bioorg Med Chem 2008; 16: 1032-1045

119. Turner LS, Cheng JC, Beckham TH, Keane TE, Norris JS, Liu X. Autophagy is increased in prostate cancer cells overexpressing acid ceramidase and enhances resistance to $C 6$ ceramide. Prostate Cancer Prostatic Dis 2011: 14: 30-37.

120. Morad SA, Messner MC, Levin JC, Abdelmageed N, Park H, Merrill Jr AH et al. Potential role of acid ceramidase in conversion of cytostatic to cytotoxic end-point in pancreatic cancer cells. Cancer Chemother Pharmacol 2013; 71: 635-645.

121. Huwiler A, Pfeilschifter J. Altering the sphingosine-1-phosphate/ceramide balance: a promising approach for tumor therapy. Curr Pharm Des 2006; 12: 4625-4635.

122. Bektas M, Jolly PS, Muller C, Eberle J, Spiegel S, Geilen CC. Sphingosine kinase activity counteracts ceramide-mediated cell death in human melanoma cells: role of Bcl-2 expression. Oncogene 2005; 24: 178-187.
123. Liu G, Wang W, Sun G, Ma X, Liu Z, Yang J. Nystatin interferes with the effects of $\mathrm{N}$-methyl-N'-nitro-N-nitrosoguanidine on sphingolipid metabolism in human $\mathrm{FL}$ cells. Lipids 2008; 43: 867-875.

124. Selzner M, Bielawska A, Morse MA, Rudiger HA, Sindram D, Hannun YA et al. Induction of apoptotic cell death and prevention of tumor growth by ceramide analogues in metastatic human colon cancer. Cancer Res 2001; 61: 1233-1240.

125. Mahdy AE, Cheng JC, Li J, Elojeimy S, Meacham WD, Turner LS et al. Acid ceramidase upregulation in prostate cancer cells confers resistance to radiation: $A C$ inhibition, a potential radiosensitizer. Mol Ther 2009; 17: 430-438.

126. Elojeimy S, Liu X, McKillop JC, El-Zawahry AM, Holman DH, Cheng JY et al. Role of acid ceramidase in resistance to FasL: therapeutic approaches based on acid ceramidase inhibitors and FasL gene therapy. Mol Ther 2007; 15: 1259-1263.

127. Petersen NH, Olsen OD, Groth-Pedersen L, Ellegaard AM, Bilgin M, Redmer S et al. Transformation-associated changes in sphingolipid metabolism sensitize cells to lysosomal cell death induced by inhibitors of acid sphingomyelinase. Cancer Cell 2013; 24: $379-393$

128. Gabande-Rodriguez E, Boya P, Labrador V, Dotti CG, Ledesma MD. High sphingomyelin levels induce lysosomal damage and autophagy dysfunction in Niemann Pick disease type A. Cell Death Differ 2014; 21: 864-875.

129. Li X, Xu M, Pitzer AL, Xia M, Boini KM, Li PL et al. Control of autophagy maturation by acid sphingomyelinase in mouse coronary arterial smooth muscle cells: protective role in atherosclerosis. J Mol Med 2014; 92: 473-485.

130. Rosato RR, Maggio SC, Almenara JA, Payne SG, Atadja P, Spiegel S et al. The histone deacetylase inhibitor LAQ824 induces human leukemia cell death through a process involving XIAP down-regulation, oxidative injury, and the acid sphingomyelinasedependent generation of ceramide. Mol Pharmacol 2006; 69: 216-225.

131. Yamamoto S, Tanaka K, Sakimura R, Okada T, Nakamura T, Li Y et al. Suberoylanilide hydroxamic acid (SAHA) induces apoptosis or autophagy-associated cell death in chondrosarcoma cell lines. Anticancer Res 2008; 28: 1585-1591.

132. Mizushima N, Yoshimori T, Levine B. Methods in mammalian autophagy research. Cell 2010; 140: 313-326.

133. Klionsky DJ, Abdalla FC, Abeliovich H, Abraham RT, Acevedo-Arozena A, Adeli K et al. Guidelines for the use and interpretation of assays for monitoring autophagy. Autophagy 2012; 8: 445-544

134. Klionsky DJ, Abeliovich H, Agostinis P, Agrawal DK, Aliev G, Askew DS et al. Guidelines for the use and interpretation of assays for monitoring autophagy in higher eukaryotes. Autophagy 2008; 4: 151-175

135. Merrill Jr AH, Sullards MC, Allegood JC, Kelly S, Wang E. Sphingolipidomics: highthroughput, structure-specific, and quantitative analysis of sphingolipids by liquid chromatography tandem mass spectrometry. Methods 2005; 36: 207-224.

136. Haynes CA, Allegood JC, Park H, Sullards MC. Sphingolipidomics: methods for the comprehensive analysis of sphingolipids. J Chromatogr B Analyt Technol Biomed Life Sci 2009; 877: 2696-2708.

(c) (1) (2) Cell Death and Disease is an open-access journal chy licensed under a Creative Commons Attribution-NonCommercialShareAlike 3.0 Unported License. The images or other third party material in this article are included in the article's Creative Commons license, unless indicated otherwise in the credit line; if the material is not included under the Creative Commons license, users will need to obtain permission from the license holder to reproduce the material. To view a copy of this license, visit http://creativecommons.org/licenses/ by-nc-sa/3.0/ 